\title{
N-(2-PIRYDYLAMINO) METHYLENEBISPHOSPHONIC ACID AS A SOLE SOURCE OF A FUNGI FUSARIUM STRAINS GROWING
}

\author{
Teresa Krzysko-Lupicka' ${ }^{1}$ Adam Sudol ${ }^{2}$ \\ 1 Independent Department of Biotechnology and Molecular Biology, Faculty of Natural Sciences and \\ Technology, University of Opole, Poland \\ 2 Department of Technology, Faculty of Natural Sciences and Technology, University of Opole, Poland, e-mail: \\ dasiek@uni.opole.pl
}

Received: 2016.06 .21

Accepted: 2016.07.26

Published: 2016.09.20

\begin{abstract}
The active substance of new herbicide generation is N-(2-pirydyloamino) methylenobisphosphonic acid. Two strains Fusarium culmorum $\mathrm{CB}_{3}$ and Fusarium oxysporum $\mathrm{XVI}$, isolated from soil treated with examined substance, were chosen to investigation of using it as a sole source of phosphorus, nitrogen or carbon in the concentrations at $1.0 \mathrm{mM}$. Interactions between the dominating strains of fungi and N-(2-pirydyloamino) methylenobisphosphonic acid, mycelium growth rate, the spore germinate index, the level chemical changes of N-(2-pirydyloamino) methylenobisphosphonic acid and $\mathrm{pH}$ were investigated after cultivation in mineral medium and its modifications. The results of growth kinetics of the studied Fusarium fungi in the presence of $\mathrm{N}$-(2-pirydyloamino) methylenobisphosphonic acid, were expressed by dry weight $\left[\mathrm{g} \cdot \mathrm{dm}^{-3}\right]$. Only Fusarium oxysporum XVI has been capable to grow in acidic medium ( $\mathrm{pH}$ 4.0) using $\mathrm{N}$-(2-pirydylamino) methylene-bisphosphonic acid as an alternative source of phosphorus. In these conditions the N-(2-pirydylamino) methylenebisphosphonic acid degradation was carried out to utilize phosphorus compounds as a source of nutrient components for this strain. The presence of N-(2-pirydylamino) methylenebisphosphonic acid receded a growth rate of mycelium but did not have an effect on spores of the tested fungi.
\end{abstract}

Keywords: fungi, biodegradation, N-(2-pirydylamino) methylenebisphosphonic acid, herbicide

\section{INTRODUCTION}

$\mathrm{N}$-(2-pirydylamino) methylenebisphosphonic acid is a compound of promising herbicidal properties [Lejczak et al. 1996, Forlani et al. 1997, Kafarski et al. 1997]. It contains two direct covalent carbon-to-phosphorus bonds which are resistant to chemical, photolytic and thermal degradation. The removal of this compound from environment would be low, when it could not be degraded by microorganisms. Therefore, application of this substance requires multidirectional ecological and toxicological studies.

Previous studies found that autochthonous soil fungi can utilize organophosphonates as nutriment and also as energetic substrate, with herbicide glyphosate being the most intensively studied [Bujacz et al. 1995, Krzysko-Lupicka et. al. 1997, Krzysko-Lupicka et. al. 1997a, Krzysko-Lupicka et. al. 2008, Tejada 2009, Shushkova et. al. 2010]. Fungi arising after Roundup (technical formulation of glyphosate) treatment for agricultural environment, in particular the presence of phytopatogens in this group is significant.

The presence of N-(2-pirydylamino)methylenebisphosphonic acid in soil leads to temporary changes of soil microorganisms, particularly the elevated growth of phytotoxic strains, especially those of Fusarium species [KrzyskoLupicka 2005]. 
The herbicides also affect the microorganisms development, what is caused by disturbances in cell metabolism, but not all of these changes lead to inhibition of microorganisms reproduction.

The goal of this study was to determine the influence of N-(2-pirydylamino) methylenebisphosphonic acid used as sole source of carbon, nitrogen, or phosphorus or both nitrogen and phosphorus on growth of Fusarium sp. and on spores germination rate index. The possibility of fungi Fusarium strains to biodegrade of this substance was also investigated.

\section{MATERIALS AND METHODS}

The Fusarium culmorum $\mathrm{CB}_{3}$ and Fusarium oxysporum XVI strains as a potentially phytopatogenic fungi were chosen for further studies. Their growth intensities and possibility of production of stain, which are either associated with mycelium or diffuse to medium in dependence on their modifications, were similar. Earlier, these fungi were selected by observing their significant growth in presence of N-(2-pirydylamino)methylenebisphosphonic acid [Krzysko-Lupicka 2005].

The N-(2-pirydylamino)methylenebisphosphonic acid (B) was used, in the concentrations of $1.0 \mathrm{mM}$, as a sole source of carbon, or nitrogen, or phosphorus or both nitrogen and phosphorus.

The pure fungal cultures were growing in full $(\mathrm{Cz})$ and mineral modification Czapek medium at $25^{\circ} \mathrm{C}$ through $1-4$ weeks. The medium modification consisted of addition of $1 \mathrm{mM}$ of $\mathrm{N}-(2-$ pirydylamino) methylenebisphosphonic acid (B) as an alternative source of following nutriments: carbon $(\mathrm{Cz}-\mathrm{C}+\mathrm{B})$; nitrogen $(\mathrm{Cz}-\mathrm{N}+\mathrm{B})$; phosphorus $(\mathrm{Cz}-\mathrm{P}+\mathrm{B})$ or nitrogen and phosphorus $(\mathrm{Cz}-\mathrm{N}-\mathrm{P}+\mathrm{B})$. The growth of fungi in full mineral (pH 5.6) and acid (pH 4.0) media was treated as controls, whereas the growth of fungi in medium without nutriment - carbon (Cz-C), nitrogen (Cz$\mathrm{N})$, phosphorus (Cz-P) or nitrogen and phosphorus $(\mathrm{Cz}-\mathrm{N}-\mathrm{P})$, was an unqualified control. The fungi population density applied to inoculate the medium was $2 \cdot 10^{6} \mathrm{cell} \cdot \mathrm{cm}^{-3}$.

After 1, 2, 3 and 4 weeks of culture in following parameters were determined:

- kinetics of the growth of the studied Fusarium by determination of mycelium dry mass ( $\mathrm{g}$ d.m. $\left.\mathrm{dm}^{-3 \cdot}\right)$ at $105^{\circ} \mathrm{C}$;

- a degree of $\mathrm{N}$-(2-pirydylamino)methylenebisphosphonic acid degradation by UV-
VIS spectrophotometry following the changes at $\lambda=316 \mathrm{~nm}$;

- a growth rate index ITW and spores germination rate index INK (\%) of tested fungi [Krzysko-Lupicka and Sudol 2008].

The obtained data have been statistically processed using one factor variance analysis and multiple range Duncan test. In parallel, the macro- and microscopic changes of studied fungi, were observed.

\section{RESULTS}

$\mathrm{N}$-(2-pirydylamino)methylenebisphosphonic acid, added to Fusarium culmorum CB3 and Fusarium oxysporum XVI cultures, as a sole source of nutriment $(\mathrm{Cz}-\mathrm{C}+\mathrm{B}, \mathrm{Cz}-\mathrm{N}+\mathrm{B}, \mathrm{Cz}-$ $\mathrm{P}+\mathrm{B}, \mathrm{Cz}-\mathrm{N}-\mathrm{P}+\mathrm{B})$ led to inhibition of fungal growth. Only in case of Fusarium oxysporum XVI a biomass increase in culture with $\mathrm{N}-(2-$ pirydylamino)methylenebisphosphonic acid used as an alternatively source of phosphorus $(\mathrm{Cz}-\mathrm{P}+\mathrm{B})$ was observed. However, it was lower when compared with the growth in full Czapek (pH 5.6) and acid (pH 4.0) media. It was, however, higher than the growth of the fungi in medium without phosphorus (Figure 1).

In parallel, the $\mathrm{pH}$ changes of tested strains after four weeks of incubation (II) in comparison with initial cultures were investigated and significant increase of $\mathrm{pH}$ in modified cultures, except $\mathrm{Cz}-\mathrm{N}, \mathrm{Cz}-$ $\mathrm{N}+\mathrm{B}$ and $\mathrm{Cz}-\mathrm{N}-\mathrm{P}$, were observed (Figure 2).

The changes of medium $\mathrm{pH}$ can be a chemical indicator of N-(2-pirydylamino)-methylenebisphosphonic acid biodegradation in presence of tested fungi or their metabolites.

The spectroscopic analysis showed, that absorption decreases only in case of Fusarium oxysporum XVI culture with N-(2-pirydylamino) methylenebisphosphonic acid used as an alternative source of phosphorus (Figure 3).

The growth rate index (ITW) showed that N-(2 - pirydyloamino) methylenobisphosphonic acid added to medium as an alternative source of nutriment led to a mycelium inhibition of $F$. oxysporum but in the case of $F$. culmorum this index was different depending on the availability of nutrients. There was no significant effect of the compound on the rate of growth in the medium with no readily available phosphorus compared to the substrate complete $(\mathrm{Cz})$ (Table 1). The spores germination 


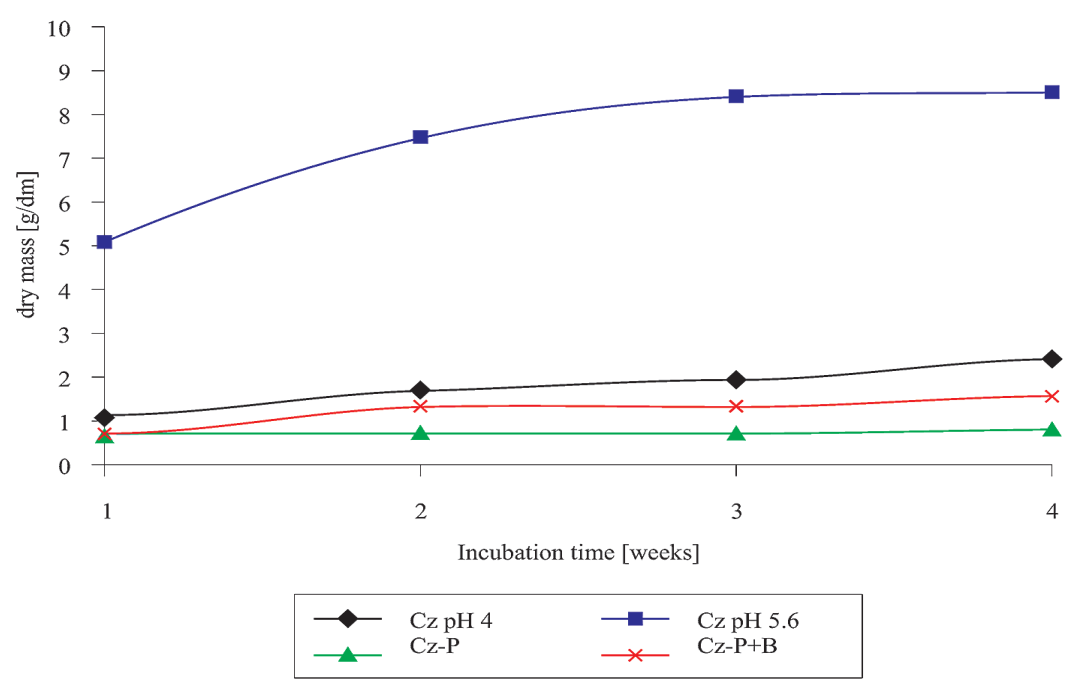

Figure 1. The kinetics of growth of Fusarium oxysporum XVI in presence of N-(2-pirydylamino)- methylenebisphosphonic acid, which served as sole source of phosphorus [Cz-P+B], medium devoid of phosphorus [Cz-P], Czapek medium pH 4 (Cz pH 4), Czapek medium pH 5,6 (Cz pH 5,6).

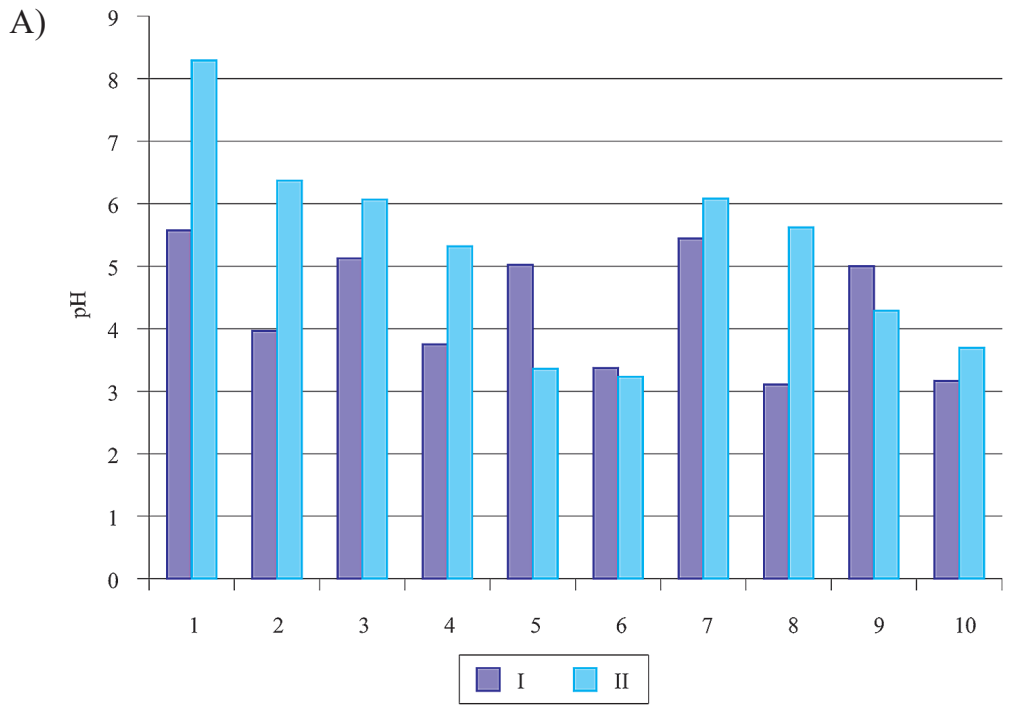

B)

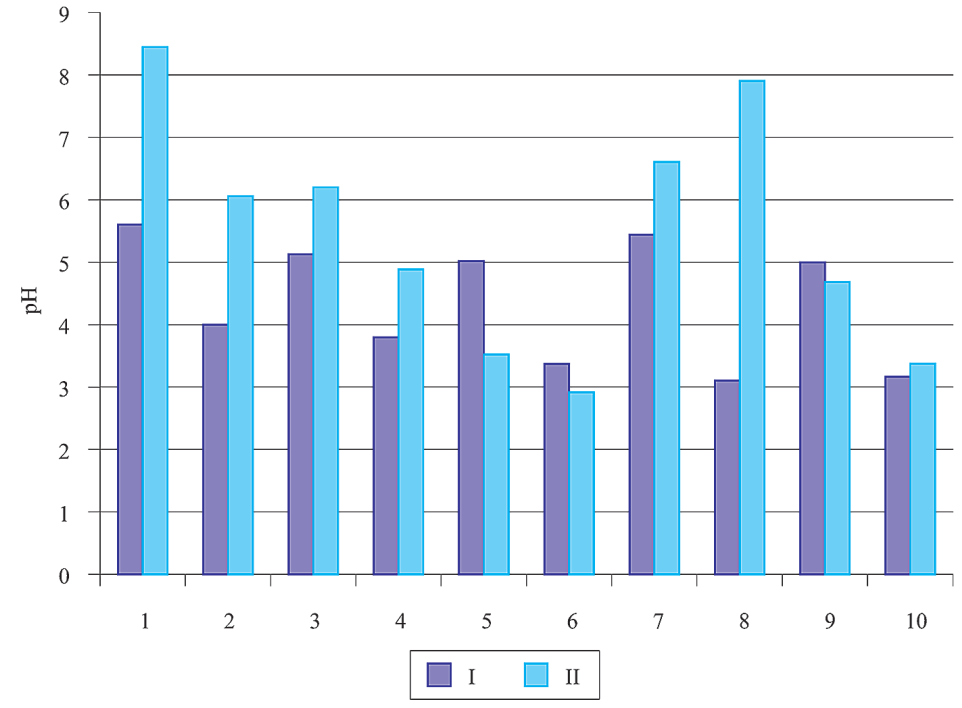

Figure 2. The $\mathrm{pH}$ changes of starting liquid cultures [I] and after four weeks [II] of incubations in the presence of A - Fusarium culmorum CB3, B - Fusarium oxysporum XVI in full $(\mathrm{Cz})$ and modified $(\mathrm{Cz}-\mathrm{X})$ medium: $\mathrm{Cz}(1)$, $\mathrm{Cz}$ pH 4 (2) Cz-C (3), Cz-C+B (4), Cz-N (5), Cz-N+B (6), Cz-P (7), Cz-P+B (8), Cz-N-P (9), Cz-N-P+B (10), where $\mathrm{B}$ is $\mathrm{N}-(2$-pirydylamino) methylenebisphosphonic acid 


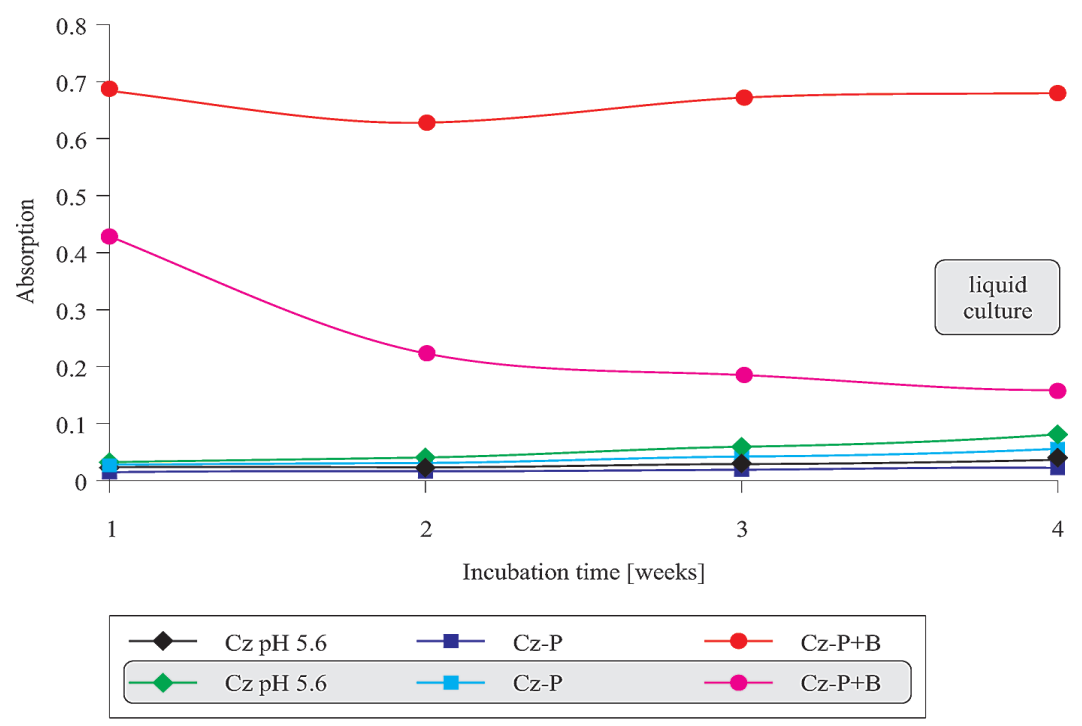

Figure 3. Spectrophotometric evaluation of the level of degradation N-(2-pirydylamino)methylenebisphosphonic acid, which served as sole source of phosphorus for Fusarium oxysporum XVI strain $[\lambda=316 \mathrm{~nm}]$.

rate index (INK) depended only on well assimilable alimentary components (spores of tested fungi were resistant to added acid) (Table 1).

The culture modifications led to formation of chlamydospores, to change in structure and colour of mycelium, and to elimination ability of stains diffusion to the medium. The stains are not only by-products of metabolism but they take part in enzymatic transmutations of fungi. The both strains did not produce stains in cultures without well assimilable sugar; in other modifications they formed stains coloured from yellow to violet. The colour was depended on fungi species. The environmental conditions may lead to a change of stain characteristics among the same strain.

The next studies ought to concentrate on analysis of by-products obtained as a result of N-(2pirydylamino) methylenebisphosphonic acid degradation by Fusarium oxysporum.
The strains fungi from Cylindrocarpon are able to utilization bisphosphonic acid served as sole source of phosphorus [Krzysko-Lupicka et al. 2002, Krzysko-Lupicka et al. 2002]. Since the earlier investigations of N-(2-pirydylamino) methylenebisphosphonic acid utilization in presence of Aspegillus niger did not give satisfactory results; the present studies indicate usefulness of some fungal strains in biodegradation of these compounds [Krzysko-Lupicka et al.1999].

\section{DISCUSSION}

Like the glyphosate N-(2-pirydylamino) methylene-bisphosphonic acid has a selective effect on soil microorganisms favoring the development of i.e. potentially phytopathogenic Fusarium fungi [Lejczak et al. 1996, Forlani et

Table 1. The influence of N-(2-pirydylamino)methylenebisphosphonic acid on spores germination rate index INK (\%) and on growth rate index ITW of Fusarium fungi

\begin{tabular}{|c|c|c|c|c|}
\hline \multirow{2}{*}{ Type of medium modification } & \multicolumn{2}{|c|}{ F. culmorum } & \multicolumn{2}{|c|}{ F. oxysporum } \\
\hline & INK\% & ITW & INK\% & ITW \\
\hline 1. $\mathrm{Cz}$ & $63.61 \mathrm{ab}$ & $57.27 a b$ & 68.17 bc & $88.73 \mathrm{c}$ \\
\hline 2. $\mathrm{Cz}-\mathrm{C}$ & $51.03 \mathrm{ab}$ & $79.54 \mathrm{~d}$ & $61.80 \mathrm{abc}$ & $87.03 \mathrm{c}$ \\
\hline 3. $\mathrm{Cz}-\mathrm{C}+\mathrm{B}$ & $59.70 \mathrm{ab}$ & $78.66 \mathrm{~d}$ & $41.71 \mathrm{a}$ & $84.06 \mathrm{c}$ \\
\hline 4. $\mathrm{Cz}-\mathrm{N}$ & $61.58 a b$ & $73.34 \mathrm{c}$ & 77.22 bc & $85.29 c$ \\
\hline 5. $\mathrm{Cz}-\mathrm{N}+\mathrm{B}$ & $43.66 \mathrm{a}$ & $74.84 \mathrm{~cd}$ & $71.08 \mathrm{bc}$ & $63.57 \mathrm{a}$ \\
\hline 6. Cz-P & $84.49 \mathrm{~b}$ & $53.75 \mathrm{a}$ & $86.58 \mathrm{c}$ & $86.73 \mathrm{c}$ \\
\hline 7. $\mathrm{Cz}-\mathrm{P}+\mathrm{B}$ & $70.89 a b$ & $59.15 b$ & 77.45 bc & $69.72 \mathrm{~b}$ \\
\hline 8. Cz-N-P & $81.59 b$ & $55.81 \mathrm{ab}$ & $72.45 \mathrm{bc}$ & $87.32 \mathrm{c}$ \\
\hline 9. $\mathrm{Cz}-\mathrm{N}-\mathrm{P}+\mathrm{B}$ & $69.98 \mathrm{ab}$ & $56.95 a b$ & $53.44 \mathrm{ab}$ & $65.72 \mathrm{ab}$ \\
\hline
\end{tabular}

$\mathrm{a}, \mathrm{b}<0.05$ statistically essential difference. 
al. 1997, Kafarski et al. 1997, Krzyśko-Łupicka 2005] proved the herbicidal activity of this acid, but there is no information about the degradative ability of autochthonous soil microorganisms yet.

Among the autochthonic Fusarium soil species of only Fusarium oxysporum XVI was capable to grow in acidic medium $(\mathrm{pH} 4.0)$ using $\mathrm{N}-(2-$ pirydylamino)methylene-bisphosphonic acid as an alternative source of phosphorus. In these conditions the N-(2- pirydylamino)methylenebisphosphonic acid degradation was carried out to utilize phosphorus compounds as a source of nutrient components for this strain. It was observed that the presence of $\mathrm{N}$-(2-pirydylamino) methylenebisphosphonic acid receded a growth rate of mycelium but did not have an effect on spores of the tested fungi.

The spectroscopic analysis suggests biodegradation of this acid results in obtaining new components which do not absorb in the analyzed region of spectra. Therefore, the biomass increase is connected with usage of phosphorus in different forms. In the other cases, the absorption changes were not observed (or a little increase in one case).

\section{CONCLUSIONS}

The research conducted on biodegradation capabilities of organophosphate active ingredients found in the new generation of herbicides, indicate the possibility of removal of these compounds on the basis of microbial potential of soil. Like in the case of glyphosate biodegradation, it is likely to be a feature of microbial strains.

\section{REFERENCES}

1. Bujacz B, Wieczorek P, Krzysko-Lupicka T, Lejczak B, Kafarski P. 1995. Organophosphonate utilization by the wild-type strains of Penicillium notatum. Appl. Environ. Microbiol. 61, 2905-2910.

2. Forlani G, Kafarski P, Lejczak B. 1997. Mode of action of herbicidal derivatives of minomethylenebisphosfonic acid. Part II. Reversal of herbicidal action by aromatic amino acids, J. Growth Regul. 16, 147-152.

3. Kafarski P, Lejczak B, Forlani G, Gancarz R, Torreilles C, Grembecka J, Ryczek A, Wieczorek P. 1997. Mode of action of herbicidal derivatives of aminomethylenobisphosphonic acids. III. Structure- activity relationship, J. Plant Growth Regul. $16,153-158$.
4. Krzysko-Lupicka T, Orlik A. 1997. The use of glyphosate as the sole source of phosphorus or carbon for the selection of soil borne fungal strains capable to degrade this herbicide. Chemosphere, 34(12), 2601-2605.

5. Krzysko-Lupicka T, Strof W, Kubs K, Skorupa M, Wieczorek P, Lejczak B, Kafarski P. 1997a. The ability of soil fungi to degrade organophosphonate carbon-to phosphorus bond. Appl. Microbiol. Biotechnol. 48, 549-552.

6. Krzysko-Lupicka T, Gajda A, Dzygiel P. 1999. Activity of soil-borne fungal strains Aspergillus niger van. Tieghem to degrade (N-piradymilo) methylenobisphosphonic acid. Abstract 51st International Symp. on Crop Protection. 4 may, Gent, Belgium, 182.

7. Krzysko-Lupicka T, Slupczynska M, Kinal S. 2002. The ability of selected strains Cylindrocarpon species to growth in presence of N-(2-pirydyloamino) methylenobisphosphonic acid served as sole source of carbon or nitrogen or phosphorus or nitrogen and phosphorus. (in) Chemical products in agriculture and environment (ed. Gorecki H, Dobrzanski Z., Kafarski P.). CZECH-POL TRADE, Prague, Brussels, Stockholm, 297-299.

8. Krzysko-Lupicka T, Slupczynska M, Kinal S. 2002a. The kinetic of growth soil-borne fungi from Cylindrocarpon species in presence of N-(2-pirydyloamino) methylenobisphosphonic acid. (in) Chemical products in agriculture and environment (ed. Gorecki H, Dobrzanski Z., Kafarski P.). CZECH-POL TRADE, Prague, Brussels, Stockholm, 300-302.

9. Krzysko-Lupicka T. 2005. The effect of N(2pirydyloamino) methylenobisphosphonic acid on activity of soil microorganisms. (in) Chemistry for Agriculture, Vol. 6, Development in production and use of new agrochemicals, (ed. Gorecki H, Dobrzanski Z., Kafarski P.), CZECH-POL TRADE, Prague, Brussels, Stockholm, 863-868.

10. Krzysko-Lupicka T, Sudol T. 2008. Interactions between glyphosate and autochthonous fungi surviving in aqueous solution of glyphosate. Chemosphere, 71, 1386-1391.

11. Lejczak B, Boduszek B, Kafarski P, Forlani G, Wojtasek H, Wieczorek P. 1996. Mode of action of herbicidal derivatives of aminomethylenobisphosphonic acids. I. Physiologic activity and inhibition of anthocyanin biosynthesis, J. Plant Growth Regul., 15, 109-113.

12. Shushkova T., Ermakova I., Leontievsky A., 2010, Glyphosate bioavailability in soil. Biodegradation 21, 403-410.

13. Tejada M., 2009, Evolution of soil biological properties after addition of glyphosate, diflufenican and glyphosate+diflufenican herbicides. Chemosphere 76(3), 365-373. 